\title{
Implementing new technologies in a middle school curriculum: a rural perspective
}

\author{
Tandra L. Tyler-Wood ${ }^{*}$ (D), Deborah Cockerham and Karen R. Johnson
}

\author{
* Correspondence: \\ tandra.wood@unt.edu \\ University of North Texas, $3940 \mathrm{~N}$ \\ Elm St, Denton, TX 76272, USA
}

\begin{abstract}
The purpose of this study was to examine the impact of a new school technology on teachers and students in rural middle schools. The study involved teachers and seventh grade students in two Title I rural Texas school districts and was framed through a constructivist lens using a project-based approach. Pre- and post-intervention surveys assessed learning and perceptions, and data were analyzed using one-way Analysis of Variance. Findings suggested that new school technology does not ensure teacher understanding or student learning. For new school technologies to be successful, significant planning, teacher training, and resources must be in place.
\end{abstract}

Keywords: Rural middle schools, Technology-integrated instruction, STEM education

\section{Introduction}

Throughout the United States, educational leaders and policy makers aspire to support students to develop twenty-first century skills that will adequately prepare them for college and career opportunities (NGSS Lead States 2013). As noted in the NGSS (NGSS Lead States 2013), all students, regardless of career interests and pathways, will require a strong K-12 science education to achieve desired workforce competencies and to be successful in a globally competitive economy (Bybee and Fuchs 2006). To achieve this goal, teachers and students are encouraged to utilize technology to enhance learning outcomes (Blanchard et al. 2016). For over a decade, United States schools have increased technology usage in an effort to drive innovation. Technology-integrated instruction can transform contemporary classrooms (Sundeen and Sundeen 2013) to promote student motivation, engagement, and achievement by providing new methods of learning, promoting independence, and enlarging the student's world (Howley et al. 2011). Many factors determine the success of technology-integrated instruction, including school resources, administrator support, teacher attitudes toward technology-integrated curriculum, adequacy of technology, student perception and use of technology, and school (Howley et al. 2011).

When digital fabrication technologies such as three-dimensional (3D) printers, laser cutters, easy-to-use design software, and desktop machine tools are integrated into schools, they can stimulate creativity and innovation (Bull et al., 2017; Beyers 2010) to move students towards science, technology, engineering, and mathematics (STEM)

(c) The Author(s). 2018 Open Access This article is distributed under the terms of the Creative Commons Attribution 4.0 International License (http://creativecommons.org/licenses/by/4.0/), which permits unrestricted use, distribution, and reproduction in any medium, provided you give appropriate credit to the original author(s) and the source, provide a link to the Creative Commons license, and indicate if changes were made. 
careers (Smith 2013). Makerspaces can be found in many schools (Bull et al. 2017), allowing students to design and build almost any tangible object (Lipson and Kurman 2013). To incorporate tools and technologies, teachers may adopt a project-based instructional approach that allows students to investigate real world problems, effectively transforming classrooms into engaging student-centered learning environments (Krajcik et al. 1994). Project-based instruction is grounded in constructivism theory (Krajcik et al. 1994), and emphasizes the meaning-making capacity of the mind as new knowledge is created (Li and Huan 2017).

While many schools in the United States have already integrated technology into classroom learning (Howley et al. 2011), this learning opportunity is not available to the same extent in all districts or schools. In comparison to urban and suburban neighborhoods, schools in rural communities more often lack the technology access to serve large numbers of underrepresented students (Sundeen and Sundeen 2013; Blanchard et al. 2016; Goodpaster et al. 2009). Inadequate funding and budgetary concerns may deter technology acquisition in rural schools, leaving students without regular access to basic tools such as computers or eliminating student opportunities to experience advanced technologies such as 3D printers (Sundeen and Sundeen 2013, p. 8).

Teachers play significant roles in the effective implementation of students' technology-enhanced learning. As teachers communicate clear objectives, pedagogical strategies, and content knowledge in their interactions with students (Tamim et al. 2011), classroom practices can be improved and transformed (Blanchard et al. 2016). Because of limited professional development opportunities, teachers often lack the skills to integrate technologies into classroom instruction (Gerard et al. 2011), a problem found more often in rural area districts/schools. Consequently, these teachers may not know how to use digital technologies to support the curriculum (Smith 2013/14).

Since technology-integrated instruction can help to address learning needs and better prepare students for future twenty-first century career opportunities, K-12 technologyenhanced learning must be explored. Closer examination is needed in order to gain a deeper understanding of practices that can support teachers' use of technology to improve student learning. The purpose of this study is to determine changes in student learning, as well as teacher integration of classroom technology, in rural middle schools after obtaining and implementing the new technology.

\section{Theoretical framework}

This paper examines rural middle school technology usage through a constructivist lens. Based on the works of Piaget (1971) and Vygotsky (1978), the constructivist learning theory advocates for authentic learning contexts based on real-life situations (Schunk 2000). Constructivists emphasize self-awareness and responsibility in learning (Hirumi 2002), and highlight the social construction of knowledge (Jaramillo 1996). Through project-based learning (Krajcik et al. 1994), learners assimilate their experiences with prior knowledge and new ideas to deepen understanding, internalize meaning (Ültanir 2012), think critically and reflectively (Nanjappa and Grant 2003), and make sense of the environment (Yager 1991). This paper encapsulates constructivist theory and project based learning by examining critical inventions in history such as the solenoid unit, determining applications for the invention and suggesting possible methods for improvements and future utilization of the invention. 
An underlying tenet of constructivism is that learning is shaped by culturally related tools that help us better understand our world (Duffy and Cunningham 1996). In light of this precept, technology has been seen as a cognitive tool that can enrich the learning environment and support new understanding (Nanjappa and Grant 2003), extending the thinking process by requiring learners to think more critically about the subject matter (Jonassen 1994). Cognitive technology tools may support memory (camera, notepad, notifications and reminders), integration and synthesis (designing a wiki, website, or Powerpoint), organization (databases, interactive graphic organizers), or other cognitive skills. Adopting a constructivist viewpoint may support the rationale for integrating technology in American middle schools.

\section{Literature review}

Differences in technology integration in rural, urban, and suburban middle schools

School districts across the country are increasing students' access to digital devices, and most American schools have some computer technologies (Howley et al. 2011). However, the development of twenty-first century skills requires more than just access to technological devices: the school district's economic base must be strong enough to provide sufficient bandwidth, hire technology specialists, support professional development, and maintain equipment (Gutierrez 2016).

Since public school funding is based upon school enrollment, smaller districts generally receive less funds than larger districts (Gutierrez 2016). Rural schools often have smaller student populations than urban and suburban districts, but tend to be more widespread geographically. Many students in rural communities travel longer distances to the physical facilities, and a larger portion of funds must go towards transporting students to and from school, leaving less funding for instructional purposes (Gutierrez 2016). Building technical infrastructure that is fast enough to support the Internet in remote areas can be an expensive process that may be prohibitive in remote areas. Wheeler (2014) found that $41 \%$ of rural schools, as compared with $31 \%$ of urban schools, lack enough bandwidth to support connectivity.

When Lu and Overbaugh (2009) examined differences in rural, urban, and suburban school teachers' perceptions of technology integration, they found that suburban schools had the highest level of technological support. Rural and suburban schools differed significantly in ability to access hardware and software, in technical support staff, and in average time to solve technical problems. Urban and suburban schools differed in access to technology integration professionals, time to solve technical problems, and in technology education opportunities. Although rural and urban schools showed comparable results, rural schools were more limited in their access to technology resources.

\section{Issues with implementation of new Technology in Schools}

\section{Administrative support}

School principals now have to assume the role of technology leaders. Schools that are successful in technology-enhanced learning are often guided by detailed plans based on philosophies and goals to be achieved (Baylor and Ritchie 2002). These plans are more widely used in urban school districts (Flanagan and Jacobsen 2003). Leadership ability, 
along with the vision to drive culture change, is critical for a successful technology enhanced learning environment (Baylor and Ritchie 2002). Principals' belief in technology-integrated teaching and learning, involvement in technology training sessions, and recognizing and rewarding teachers' endeavors to incorporate technology into classroom learning, are key factors that contribute to success (Maurer and Davidson 1998).

Furthermore, school principals help to cultivate credibility and respect by modeling technology usage (Baylor and Ritchie 2002). However, like teachers (Gerard et al. 2011), administrators are often not prepared for their role as technology leaders and often lack the "pedagogical vision and experience to guide teachers" (Flanagan and Jacobsen 2003, p. 128). Too often the limited resources are spent on acquiring equipment, with little or no emphasis on organizational culture change or technical support (Flanagan and Jacobsen 2003).

\section{Teacher preparedness}

According to a 2015 survey, approximately $90 \%$ of teachers see technology as an essential part of education (Roland 2015). However, 60\% of teachers feel that they need more technology training, and 37\% claim that they do not know how to implement technology in the classroom (Roland 2015). Preparing teachers to use technology in the classroom requires more than just familiarity with the technology; teachers must learn how to best implement the technology to help students develop relevant skills (Lambert and Gong 2010).

In measuring preservice teachers' technology literacy skills, Dinçer (2018) found that even those who scored themselves as highly "technology literate" were lacking in technology knowledge and skills. Dincer concluded that teacher training should not only include technology literacy courses, but must also integrate teaching activities with the technology. Design technology based on digital fabrication can support teachers in using technology to introduce engineering and math concepts (Berry et al. 2010).

\section{Teacher technology skills in rural districts}

Classroom technology integration is often related to teachers' technological skills and confidence. However, in rural settings, limited funding and the community's remote location may interfere with the availability of technological resources (Bjerede 2018). In 2016, 39\% of rural Americans lacked Broadband access (Federal Communications Commission, 2016), and many could not afford to install the expensive Internet infrastructure in their isolated communities (Thacker 2017). In addition, inadequate training opportunities may impact the teacher's motivation to strengthen personal technology skills (Lu and Overbaugh 2009; Howley et al. 2011). Rural districts may not have the funds to hire technical specialists, and costs for maintaining equipment can be expensive. Even when training is provided, rural teachers may not attend. Teachers who chose not to attend professional development and infrequently used technology in the classroom resisted primarily due to difficulties with the technology, limited time and support, and/or the need to address "high stakes" testing (Howley et al. 2011). Rural communities may also avoid implementation of new and emerging technologies, possibly due to concerns that technology may change the "small town feel" (Bjerede 2018). 
About one third of all United States schools are located in rural areas (Bjerede 2018), and the challenges are as varied as the schools themselves. Even in schools that are committed to the use of technology, technology may be used primarily to support traditional teaching practices (Rakes et al. 2006), limiting the innovative opportunities provided by technological resources. Whatever the setting, teacher skills and confidence in regard to technology are particularly important in rural schools (Larson and Murray 2008), and will be essential in supporting the development of twenty-first century skills.

\section{Student readiness for technology-integrated learning}

In a classroom with instructional technology capabilities, the interaction between students and teachers tends to be more rewarding (Flanagan and Jacobsen 2003). Students value resources and appreciate access to Internet-provided information (Li 2007). However, students who live in lower socio-economic areas may have limited access to computers and other technological devices at home (Flanagan and Jacobsen 2003).

In a study of middle school technologies and academic engagement (Spires et al. 2008), researchers held student focus groups to determine student perceptions of school technology usage. Many students expressed concern that access to technology at school was overly restrictive, and felt that teachers were somewhat disconnected with their technology needs. D'Souza and Wood (2004) reported that students sometimes demonstrate mistrust of software and prefer traditional approaches to learning, which may be linked to the lack of teacher preparation to use the technology (Gerard et al. 2011). Students voiced the need for more current and frequent use of technology in schools (Li 2007), and felt that the use of simulations, visual models, and graphic tools enhanced their learning. Many also mentioned that additional technology opportunities at school could help motivate classwork (Spires et al. 2008) and boost confidence levels (Li 2007), particularly if the technology supported interactive and other creative technology options. Overall, many students appreciate the ease and speed of obtaining accurate, up-to-date information. Students like the flexibility of navigating through information at their own pace, and appear to be enthusiastic toward technology-integrated learning (Li 2007).

\section{$3 D$ technologies}

Since the addition of 3D printers in middle and high schools, students are more motivated through projects that involve hands-on experience in STEM-focused areas, for example, robotics and basic electronics (Lacey 2010). Lacey defined 3D printing as "an additive manufacturing technology in which a three-dimensional object is formed by adding layers of material" (p. 17). Through the use of 3D printing, students learn contemporary product design and manufacturing processes that are used in industry. According to Ford and Minshall (2016), the adoption of 3D printing is still limited in some elementary and secondary schools. While the technology is becoming more prevalent, Moorefield-Lang (2014) commented on the importance of learning by trial and error and exercising patience.

The benefits of 3D printing for middle school students are numerous. Results from a study revealed that three-view diagrams and 3D printed solid models enhance the 
development of spatial abilities, such as mental rotation, spatial visualization (Huang and Lin 2017), and mathematical knowledge (Ford \& Minshall, 2016). Students in a small rural school in Michigan experienced cross-cultural benefits from the use of 3D printing by improving oral communication skills through the opportunity to present the learning Schelly et al. (2015).

It is also important to provide training for teachers to ensure the effective utilization of new classroom technology to improve learning. Studies have focused on 3D technology training for teachers. Schelly et al. (2015) reported on the success of a 3-day workshop for teachers on open-source 3-D printing technologies and its potential role in the classroom. In teams, teachers were able to build and use 3-D printers during the workshop while gaining a greater recognition of the potentials of the technology to empower learning and transform education. In a study, Al-Mouh et al. (2016), reported the success of teacher workshop on new trends in computing technologies, including 3D printing. Teachers had the opportunity to apply what was learned and expressed overall satisfaction of the workshop.

\section{Future career opportunities associated with 3D}

Student understanding of current learning activities in relation to future career needs is critical for a successful career (Wood and Kaszubowski 2008). Students must recognize the importance of technology-enhanced learning as they prepare for future career opportunities to meet workforce demands (Li 2007; Spires et al. 2008). Technology instruction can promote students' higher order thinking skills through improved cognitive functions, thinking processes, and intellectual capacities, enabling students to think more critically, become more creative problem solvers (Baylor and Ritchie 2002), and develop technology and communication skills. However, rural middle school students may experience lack of exposure to career options, including STEM careers (Wood and Kaszubowski 2008).

Many career opportunities, including engineering, architecture, construction Russell et al. (2014), manufacturing, art, education, and medicine (Murphy and Atala 2014) are linked to digital fabrication technologies. Science-related occupations often require 3D fabrication technologies. Because digital fabrication allows individuals to design and develop objects at any time, increasing access to these technologies will challenge conventional models of business and education (Gershenfeld 2012). In general, STEM education and careers can potentially be improved through the use of 3D printing technologies. The general shortage of skilled individuals for the workplace indicates that students must be empowered to become future digital innovators. The review of the literature suggests that an examination of practices that can support teachers' use of technology to improve student learning is critical.

\section{Method}

\section{Curriculum}

The Solenoid Unit of Instruction (http://www.maketolearn.org/), developed through the National Science Foundation (NSF) Innovative Technology Experiences for Students and Teachers (ITEST) funding, contains five lab activities, two make activities, and one invent activity Tyler-Wood (2018). A solenoid is a coil of wire that acts like a 
magnet when a flow of electricity passes through it (Solenoid n.d.). At the implementation school, a Maker Space was added to the library to allow for implementation of the solenoid unit. While this space was available for use by all teachers in the school, it was reserved at times for Solenoid Unit projects.

The Solenoid Unit consists of lessons that are sequenced to lead the learners from a baseline toward full mastery of the content and processes involved. Each lab activity is guided by essential questions, and teaches key concepts and skills that are utilized in the make activities. The culmination of the unit is the invent activity, where all previous learning is utilized in new and creative ways. Through this project, students reconstructed a historical invention (solenoid) with pedagogical support involving the following four phases to promote student learning:

1. Eliciting students' knowledge of phenomena related to classic inventions and their ideas about related science and engineering concepts underlying the inventions;

2. Introduction of new knowledge that may support, expand, or even conflict with students' ideas through the use of pivotal cases grounded in historic inventions;

3. Comparison of students' science and engineering concepts with observed phenomena, to determine how students' existing ideas may conflict with, or extend the new ideas related to newly introduced phenomena; and.

4. Reflecting and refining students' science and engineering knowledge to address gaps and discrepancies between anticipated results and actual outcomes, thus, allowing students to successfully reconstruct and potentially modify the historical invention (Bull et al. 2013)

The goal for the students was not to create an exact replica of the invention studied, but to reinterpret and reinvent the device using technology available in the Maker Space. Teachers were presented with previously developed lesson plans and taught those lesson plans. Teaching the unit took two weeks, with final project presentations occurring six weeks after the initiation of the unit.

\section{Teachers}

All 24 teachers assigned full-time to the implementation school had access to the MakerSpace funded through the solenoid project. At the end of the Solenoid Unit, the Maker Space was left intact for the future use of the teachers and students. All teachers at the school received brief information on 3D printing, and four teachers at the school assumed responsibility for teaching the Solenoid Unit to student participants. Prior to teaching the unit, the four middle school teachers participated in two three-hour training sessions. During these sessions, unit lesson plans were reviewed and materials for teaching the unit were distributed. Information on the use of the 3D printer was provided to the teachers by the printer's manufacturer in a three hour, hands-on session. Procedures for administering the pre-test and post-test were covered. These four teachers met with students for two weeks during the students' scheduled science class time.

\section{Students}

Seventh graders in two Title I rural Texas school districts participated in this study. The two school districts were chosen based on access and similarities in demographics. 
School I (Solenoid Unit participant) is a middle school that houses approximately 400 seventh and eighth grade students. Roughly $70 \%$ of students are ethnically white, $23 \%$ are Hispanic students, and 3\% are African Americans. The remaining students are Native American, Asian, or biracial. This campus has an economically disadvantaged population of $45 \%$. School 2 (contrast school) is a middle school with a population of 220 students in grades seven and eight. The ethnic distribution of this campus includes 61\% white, 31\% Hispanic, 2\% African American, and 6\% Native American, Asian, or biracial. $64 \%$ of total students at School 2 are economically disadvantaged. A flu epidemic and Internet accessibility issues further impacted data collection, particularly at the intervention site, so not all students completed both pre-test and post-test assessments at either site.

\section{Data collection}

Student surveys were administered by the participating teachers and were completed online through Survey Monkey. Pre-intervention data were gathered prior to the initiation of the sponsored study in February 2017. Post-intervention data was collected from all participants in May 2017. The actual number of students completing each assessment varied, since some students' assessments were incomplete and other students were absent when specific assessments were given. Tables 1 and 2 lists the number of students whose data was analyzed for one-way Analysis of Variance (ANOVAs). Table 3 lists the number of teachers whose data was analyzed for the t-tests. For participation in the t-test analysis, teachers needed to be present for both the pre- and post-intervention assessments. Data was not used for students who did not complete a survey or who were absent when a survey was taken.

\section{Student instruments}

The International Association for the Evaluation of Educational Achievement (IEA) has developed an assessment known as TIMSS (Trends in International Mathematics and Science Study). TIMSS is a series of international assessments of the mathematics and science knowledge of students around the world. The participating students come from a diverse set of educational systems in terms of economic development, geographical location, and population size. In each of the participating educational systems, a minimum of 4500 to 5000 students is evaluated. Contextual data about the conditions in which participating students learn mathematics and science are collected from the students, their teachers, principals, and parents via questionnaires. Fifty percent of the items developed for the TIMSS are annually released to educators for classroom usage (Stansell 2016). The TIMSS Limited (TIMMS-L) Assessment is derived from released questions from the TIMSS test. A series of 45 questions were provided to three STEM experts. Based on a juried decision process, seven questions were selected that most

Table 1 T-tests indicating changes in teacher scores prior to and post-intervention

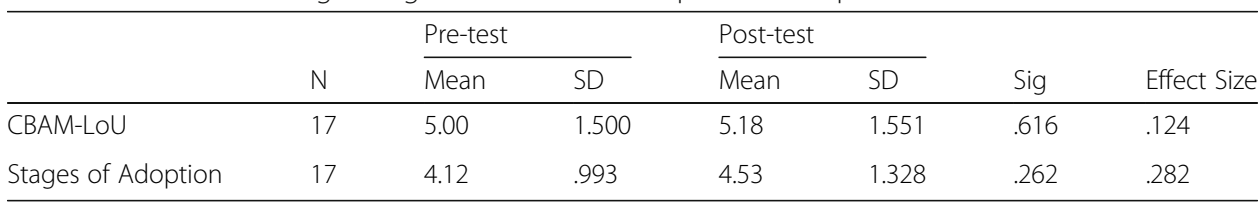


Table 2 One-way repeated measures ANOVA comparing means across groups on the TIMSS-L

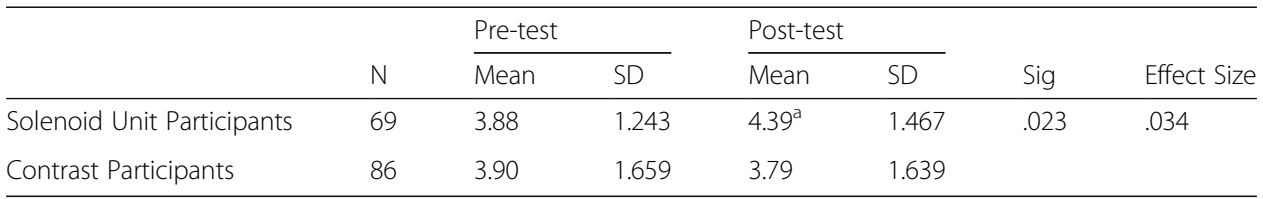

a-Follow-up t-tests indicate that Solenoid Unit participants have higher post-test scores when compared to their pre-test scores

closely related to the curriculum taught in the Solenoid Unit of instruction and the 3D printing activities.

\section{Solenoid instrumentation}

Eighth grade students in three different classes of a physical science course took the Solenoid Assessment prior to participating in the unit. The assessment consisted of multiple- choice and open-ended questions designed to evaluate participants' understanding of the concepts associated with the solenoid unit. Included items were retrieved from the following sources:

- TIMSS;

- Prentice Hall Physical Science Concepts in Action (Wysession, Frank, \& Yancopoulos, 2011) by Pearson Education;

- The physical science curriculum framework (eighth-grade) published by the Virginia Department of Education;

- Albemarle County Public Schools' Physical Science Matrix; and.

- STEM educators affiliated with the University of Virginia.

The assessment was not validated through formal measurement testing. However, content area experts in science, mathematics, and instructional technology provided iterative feedback during the development of the assessment tool (Standish 2017).

\section{Teacher instruments}

Concerns-based Adoption Model-Levels of Use (CBAM-LoU). The CBAM-LoU v1.1 instrument is a self-assessment measure targeted toward describing behaviors of innovators as they progress through various levels of use. The instrument is based on the eight levels of use defined by Loucks, Newlove, \& Hall, (1975). The levels of use are: (0) Non-Use, (I) Orientation, (II) Preparation, (III) Mechanical Use, (IVA) Routine, (IVB) Refinement, (V) Integration, and (VI) Renewal. The instrument is time efficient to use as an indicator of an educator's progress along a technology utilization continuum.

Table 3 One-way repeated measures ANOVA comparing means across groups on the Solenoid assessment

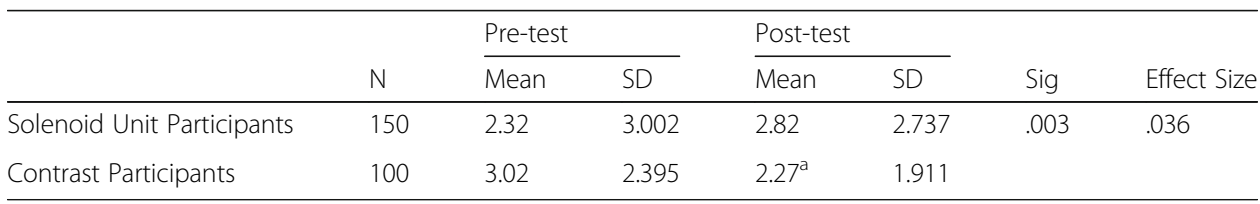

a-Follow-up t-tests indicate that contrast group participants have significantly lower post-test scores when compared to their pre-test scores 
Because the CBAM-LoU instrument is a single item survey, internal consistency reliability measures are not provided (Knezek and Christensen 2018).

Stages of Adoption of Technology (SA). The SA (Stages v1.1) instrument is a quick self-assessment used to measure the impact of information technology training as well as trends over time. It is derived from the stages presented by Russell et al. (2014) in research assessing adults learning to use electronic mail. Russell's stages included: (1) awareness, (2) learning the process, (3) understanding the application of the process, (4) familiarity and confidence, (5) adaptation to other contexts, and (6) creative applications to new contexts. In the SA instrument (Christensen, 1997; Christensen and Knezek 1999) the stage descriptions are generalized to make them appropriate for any information technology.

Because the SA instrument is a single item survey, internal consistency reliability measures cannot be calculated for data gathered through it. However, a high test-retest reliability estimate (.91) was obtained from a sample of $525 \mathrm{~K}-12$ teachers from a metropolitan north Texas public school district during August 1999. A Pearson product-moment correlation was calculated between the two reported Stage measures as a form of test-retest reliability. The resulting value of .91 indicates high consistency for these educators on reported stages (Christensen and Knezek 1999).

The following research questions were examined:

1. Do teachers participating in the Solenoid Unit of Instruction increase in their level of adoption of technology?

2. Do teacher participants in the Solenoid Unit of Instruction increase in their level of use of new technology?

3. Do student participants in the Solenoid Unit of Instruction increase in their level of knowledge of the solenoid?

4. Do student participants in the Solenoid Unit of Instruction increase in their level of understanding of concepts associated with 3D printing?

\section{Results}

Teacher results

The CBAM-LoU was administered to all teachers in the school prior to implementation of the project and after implementation of the project. Seventeen out of 25 teachers participated in the pre- and post-intervention surveys. See Table 1. A paired t-test indicated no significant difference in the scores for the CBAM-LoU of an Innovation pre-test $(\mathrm{M}=5.00, \mathrm{SD}=1.500)$ and post-test $(\mathrm{M}=5.18, \mathrm{SD}=1.551$ conditions; $\mathrm{t}(16)=.511, p=.616$. Using Cohen's $\mathrm{d}$, a very small effect size of .124 was produced. Although 25 teachers had access to the new 3D technology provided in a library-based maker space, four teachers assumed primary responsibility for teaching the solenoid unit of instruction. Those teachers' scores increased from a mean of 4.667 to a mean of 5.667. Although an increase in scores is noted, the limited number of participants does not allow for statistical analysis.

The SA was administered to all teachers in the school prior to implementation of the project and after implementation of the project. Seventeen out of 30 teachers participated in the pre- and post-intervention surveys. See Table 1. A paired t-test indicated 
no significant difference in the scores for the SA pre-test $(M=4.12, S D=.993)$ and post-test $(\mathrm{M}=4.53, \mathrm{SD}=1.328$ conditions; $\mathrm{t}(16)=1.163, p=.262$. Using Cohen's $\mathrm{d}$, an effect size of .282 was recorded. This effect size is considered to be between small and moderate. Scores of the four teachers who assumed primary responsibility for teaching the solenoid unit of instruction increased from 3.667 to 4.333. Statistical analysis was not conducted on this data because of the small number.

\section{Student results}

\section{Instrument: TIMSS-L}

A one-way repeated measures ANOVA utilizing between group factors was conducted to compare the effect of time on test scores on the TIMSS L (time $1=$ prior to intervention vs time 2 =post-intervention). No significant effect was associated with time (see Fig. 1), Wilk's Lambda $=.985, \mathrm{~F}(1,153)=2.297, p=.132$. Overall, pre-test scores were no different than post-test scores. In addition, scores over time among the two groups were compared. Significant differences were noted, Wilk's Lambda $=.966$, $\mathrm{F}(1,153)=5.306, p=.023)$. Follow-up t-test were conducted to determine differences between the two groups. A paired t-test indicated a significant difference in the scores between the solenoid unit group's pre-test $(\mathrm{M}=3.88, \mathrm{SD}=1.243)$ and post-test $(\mathrm{M}=$ $4.39, \mathrm{SD}=1.467$ scores; $\mathrm{t}(68)=3.419, p=.001$. Using Cohen's $\mathrm{d}$, a medium effect size of .412 was recorded. A paired t-test indicated no significant difference in the scores for the contrast group's pre-test $(\mathrm{M}=3.90, \mathrm{SD}=1.659)$ and post-test $(\mathrm{M}=3.79, \mathrm{SD}=1.639$ scores; $\mathrm{t}(85)=.508, p=.613$ (Fig. 1 ).

\section{Instrument: Solenoid assessment}

A one-way repeated measures ANOVA utilizing between-group factors was conducted to compare the effect of time on test scores on the Solenoid Assessment (time $1=$ prior to intervention vs time 2 = post-intervention). No significant effect was associated with time (See Fig. 2), Wilk's Lambda $=.999, \mathrm{~F}(1,248)=.366, p=.546$. Overall, pre-test scores were no different than post-test scores. In addition, scores over time between the two groups were compared. Significant differences were noted, Wilk's Lambda $=.964, \mathrm{~F}(1,248)=9.160, p=.003)$. Follow-up $\mathrm{t}$-tests were conducted to determine differences between the two groups. A paired t-test indicated no significant difference in the scores for the solenoid unit group's (group 1) pre-test $(\mathrm{M}=2.32, \mathrm{SD}=3.002)$ and post-test $(\mathrm{M}=2.82, \mathrm{SD}=2.737$ scores; $\mathrm{t}(149)=1.715, p=.088$. A paired $\mathrm{t}$-test indicated there was a significant difference in the scores for the contrast group's (group 2) pre-test $(\mathrm{M}=3.02, \mathrm{SD}=2.395)$ and post-test $(\mathrm{M}=2.27, \mathrm{SD}=1.911$ scores; $\mathrm{t}(99)=2.953, p=.004$. The contrast group's scores on the Solenoid Unit assessment actually decreased over time (Fig. 2).

\section{Discussion}

\section{Teacher data}

No significant changes were noted in comparisons of teachers' pretest and posttest scores on either the CBAM-LoU or the SA. Open-ended comments at the end of the teacher surveys indicated that some teachers continued to be unaware of the existence of the Maker Space and the associated Solenoid Unit even after the 3D technology was 


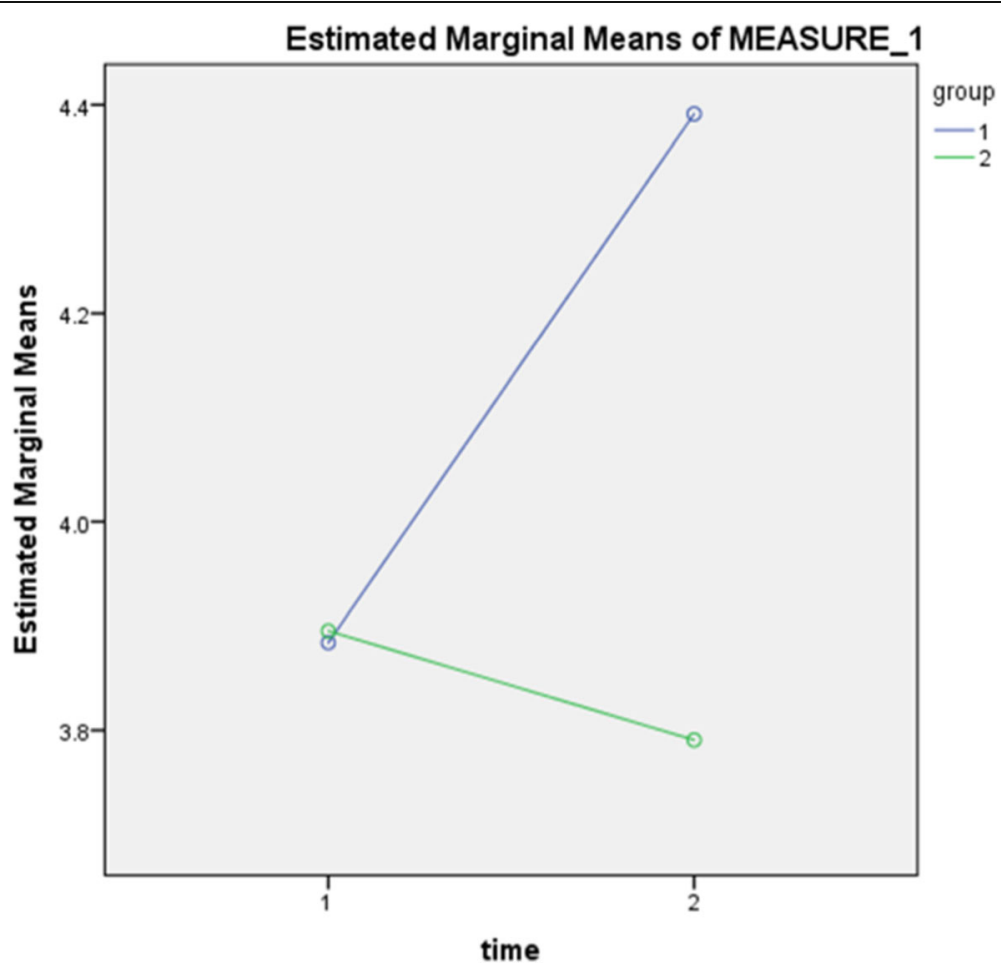

Fig. 1 TIMSS score changes by group prior to and post-intervention, displays changes between pre and post test scores for students' TIMSS scores. The experimental group (group 1) is compared to the contrast group (group 2). Scores between the two groups are initially similar, however, the experimental group performs significantly better after participating in the instructional unit on the solenoid

made available to the school for a semester. Merely placing technology and a new curriculum in the school did not impact teachers' scores. It was noted that teachers who participated in direct instruction on the 3D printer and the Solenoid Unit did show an increase in scores on the CBAM-LoU and the SA measures. However, the number of teachers impacted (4) was too few for statistical analysis. These data lend support to Dinçer (2018) findings that merely making technology available is not sufficient. Integrating teacher training with the technology is essential.

$\mathrm{Lu}$ and Overbaugh (2009) found differences in technological support when comparing suburban and rural schools. Rural and suburban schools differed significantly in the ability to access hardware and software, in technical support staff, and in average time to solve technical problems. In the current study, teacher comments in open-ended questions at the end of the surveys indicated that the rural school where the Solenoid Unit was implemented experienced significant hardware issues. Specifically, the number of available working computers for teaching was an issue that impacted instruction. Although Lu and Overbaugh documented similar issues almost a decade earlier, issues with hardware support and availability appear to still be a concern. Hopefully, it will not take another decade to address hardware support and availability in rural schools. Clearly, a nationwide initiative is needed to make much-needed technology available to all teachers in rural, urban, and suburban settings. On the open-ended survey, one teacher expressed concern over teaching the Solenoid Unit instead of providing additional focus on the "required curriculum." Howley et al. (2011) noted similar concerns, indicating that innovative technology is often not adopted because of the need to 


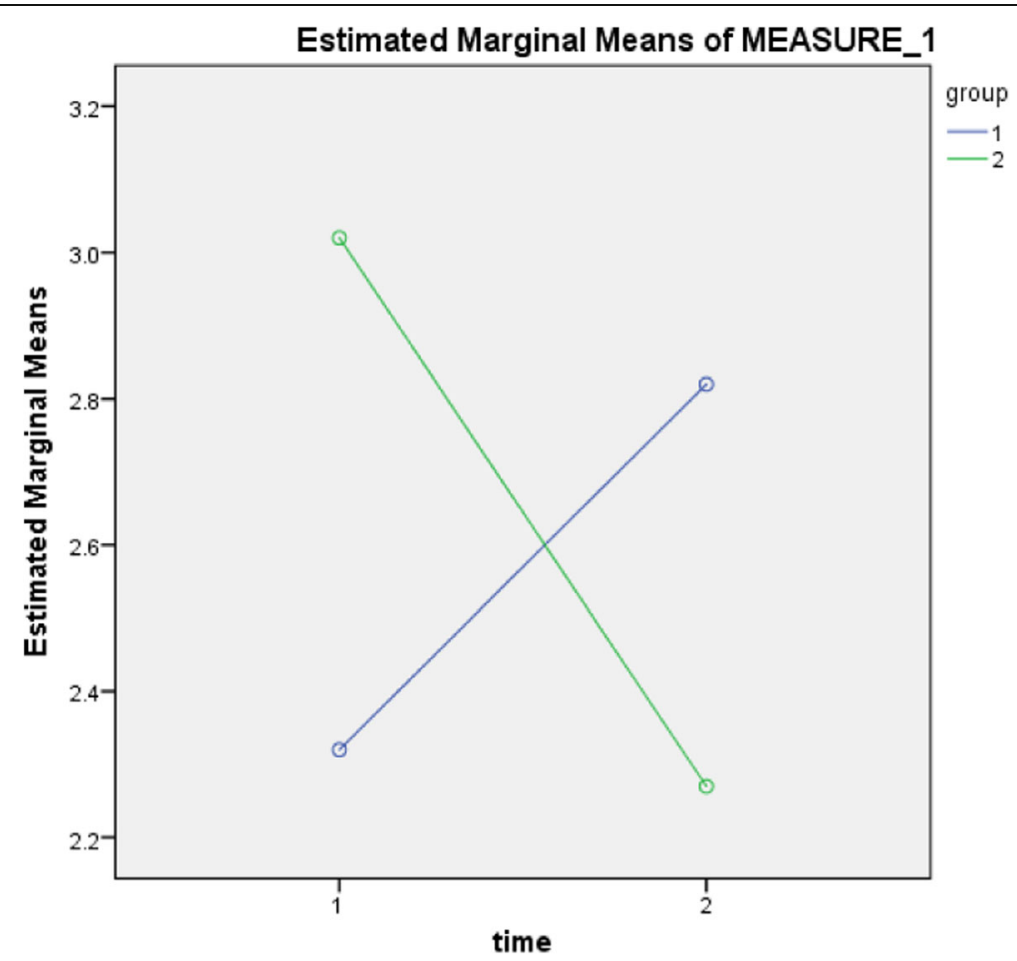

Fig. 2 Depicting Solenoid Unit score changes by group prior to and post-intervention, displays changes between pre and post test scores for students participating in the solenoid unit compared to the contrast group. Scores between the two groups on pre-tests and post-test are not significantly different

focus on high stakes testing. Because the Solenoid Unit is not directly related to the required seventh grade curriculum in Texas, at least one teacher had concerns with teaching the unit. Although the Solenoid Unit is linked to the National Science Standards, it may be important to link the curriculum to state and even local standards so that teachers understand that new technologies can facilitate acquisition of adopted standards. It is important for teachers to understand how new technologies and strategies can be used to teach the required curriculum.

\section{Student}

Student participants in the Solenoid Unit showed an increase in test scores on the TIMSS-L when compared to a contrast group of similar students who did not participate in the Solenoid Unit. The items on the TIMSS-L were selected by "experts in the field" to reflect knowledge a student could master by working with scans and a 3D printer. The content measured on the TIMSS-L was specific to 3D printing rather than to the Solenoid Unit. Clearly, there is value in increasing student gains on the TIMSS-L. The items are part of a larger testing endeavor that measures various nations' student skill sets in critical STEM subjects. The fact that students increased in their knowledge, as evidenced by their scores, is quite noteworthy. However, we cannot determine if the gain was directly related to participation in the Solenoid Unit, or if any unit of instruction that effectively introduced 3D printing into the curriculum might result in similar gains. Additional research should be conducted to determine the role that the Solenoid Unit played in student test score gains on the TIMSS-L. 
Student participants showed no significant gain on the Solenoid Unit Achievement Test after participating in the unit. In contrast, significant gains in achievement were noted when the Solenoid Unit was initially taught in a small city middle school environment in Virginia Standish et al. (2016). The demographics of the two schools seemed similar on racial and income factors, but several differences were noted in the participants in the two studies. The small city group was comprised of eighth graders taking the engineering course as an elective. The rural group was composed of seventh grade participants in a required seventh grade science class. However, the small city group had already had access to 3D printing for over four years, while 3D printing was new technology in the rural district. In addition, the small city school group was taught by an engineer, while the science teachers teaching the Solenoid Unit in the rural district had minimal experience with Solenoids. An investigation of factors that foreshadow academic success with the Solenoid Unit is essential for understanding relevant instructional practices. Factors to consider should include teacher expertise and training, availability of technology, experience with the 3D printer, and students' interest in engineering.

\section{Conclusions}

When implementing new technology or research in rural districts, one cannot assume that existing fundamental technology such as computer access is available or that the existing technology is well-serviced. Prior to implementing new innovations, checking existing infrastructure and support is a critical step. Additional personnel and hardware may need to be added to the budget to support the integration of new technology into a school. New technology integration takes time and planning. Although the 3D technology was in the school for a semester prior to final data collection and available for all teachers' use, three teachers indicated they did not know what a Solenoid was and had no experience with 3D printing. The current project directly impacted only four teachers, the 3D printing technology was made available to the entire school.

In future studies, the role of teacher commitment to the project and new technology should be examined. For new technology to be accepted in a new environment, it is important to help teachers match the technology to their lesson plans. For a new technology to be adopted by a school, significant planning, teacher training, and resources need to be in place. Training may need to be phased in so that all teachers can acquire skills with new technology.

\footnotetext{
Abbreviations

3D: Three dimensional; ANOVA: Analysis of Variance; CBAM-LoU: Concerns-based Adoption Model-Levels of Use; IEA: Evaluation of Educational Achievement; ITEST: Innovative Technology Experiences for Students and Teachers; N: Sample size/Number; NGSS: Next generation science standards; NSF: National Science Foundation; SA: Stages of Adoption of Technology; SD: Standard Deviation; STEM: Science, technology, engineering, and mathematics; TIMSS: Trends in International Mathematics and Science Study; TIMSS-L: Trends in International Mathematics and Science Study-Limited
} 
Authors' contributions

$\Pi T-W$ is the principal investigator for this work. DC is a research assistant affiliated with the supporting grant. $\mathrm{KJ}$ is an assistant professor with expertise in STEM job opportunities. All authors read and approved the final manuscript.

\section{Competing interests}

The authors declare that they have no competing interests.

\section{Publisher's Note}

Springer Nature remains neutral with regard to jurisdictional claims in published maps and institutional affiliations.

Received: 11 July 2018 Accepted: 26 September 2018

Published online: 10 October 2018

\section{References}

N. Al-Mouh, H.S. Al-Khalifa, S.A. Al-Ghamhi, N. Al-Onaizy, N. Al-Rajhi, W. Al-Ateeq, B. Al-Habeeb, in 15th International Conference on Information Technology Based Higher Education and Training (ITHET), Istanbul, 2016. A professional development workshop on advanced computing technologies for high and middle school teachers (2016), pp. 1-4

G. Bull, J.Garolfolo, D. Slykhuis, S. Barbato, T. Tyler-Wood. American Innovations in an Age of Discovery, Grant funded by the National Science Foundation No. 1510289. (2013)

A.L. Baylor, D. Ritchie, What factors facilitate teacher skill, teacher morale, and perceived student learning in technology-using classrooms? Comput. Educ. 39, 395-414 (2002)

R.Q.R.Q. Berry, G. Bull, C. Browning, C. Thomas, K. Starkweather, J. Aylor, Preliminary considerations regarding use of digital fabrication to incorporate engineering design principles in elementary mathematics education. Contemp Issues Technol Teach Educ 10(2), 167-172 (2010)

R.N. Beyers, Nurturing creativity and innovation through FabKids: A case study. J. Sci. Educ. Technol. 19(5), 447-455 (2010)

M. Bjerede, (2018). Rural districts face challenges and opportunities with technology access. Accessed 27 June 2018, from https://edtechmagazine.com/k12/article/2018/01/rural-districts-face-challenges-and-opportunities-technology-access

M.R. Blanchard, C.E. LePrevost, A. Dell Tolin, K.S. Gutierrez, Investigating technology-enhanced teacher professional development in rural, high poverty middle schools. Educ. Res. 45(3), 207-220 (2016)

R.W. Bybee, B. Fuchs, Preparing the 21 st century workforce: A reform in science and technology education. J. Res. Sci. Teach. 43(4), 349-352 (2006)

R. Christensen, G. Knezek, Stages of adoption for technology in education. Comput. New Zealand Schools 11(3), 25-29 (1999)

S. D'Souza, L. Wood, Secondary students' resistance toward incorporating computer technology into mathematics learning. Math. Comput. Educ. 37, 284-295 (2004)

S. Dinçer. Are preservice teachers really literate enough to integrate technology in their classroom practice? Educ. Inf. Technol. 23, 2699 (2018) https://doi.org/10.1007/s10639-018-9737-z

T.M. Duffy, D.J. Cunningham, in Foundations for Research in Educational Communications and Technology. Chapter 7: Constructivism: Implications for the Design and Delivery of Instruction (Indiana University, Bloomington, 1996)

L. Flanagan, M. Jacobsen, Technology leadership for the twenty-first century. Principal. J. Educ. Adm 41(2), 124-142 (2003)

L.F. Gerard, K. Varma, S.B. Corliss, M.C. Linn, Professional development for technology-enhanced inquiry science. Rev. Educ. Res. 81(3), 408-448 (2011)

N. Gershenfeld, How to make almost anything: The digital fabrication revolution. Foreign Affairs 91(6), 43-57 (2012)

K.P.S. Goodpaster, O.A. Adedokun, G.C. Weaver, Teachers' perceptions of rural STEM teaching: Implications for rural teacher retention. Rural. Educ. 33(3), 9-22 (2009)

D. Gutierrez, Little school on the prairie: the overlooked plight of rural education. Harvard Business Review. Accessed 28 June 2018, from http://harvardpolitics.com/united-states/little-school-prairie-state-rural-education-twenty-first-century-america/ (2016)

A. Hirumi, Student-centered, technology-rich learning environments (SCenTRLE): Operationalizing constructivist approaches to teaching and learning. J. Technol. Teach. Educ. 10(4), 497-537 (2002)

A. Howley, L. Wood, B. Hough, Rural elementary school teachers' technology integration. J. Res. Rural. Educ. 26(9), 1-13 (2011)

T. Huang, C. Lin, From 3D modeling to 3D printing: Development of a differentiated spatial ability teaching model. Telematics 34(2), 604-613 (2017)

J.A. Jaramillo, Vygotsky's sociocultural theory and contributions to the development of constructivist curricula. Education $117(1), 133(1996)$

D.H. Jonassen, Technology as cognitive tools: Learners as designers. ITForum Paper 1, 67-80 (1994)

G. Knezek, R. Christensen, (2018). Concerns Based Adoption Model: Levels of Use (CBAM LoU). Retrieved, July 5, 2018, from https://iittl.unt.edu/content/concerns-based-adoption-model-levels-use-cbam-lou

J.S. Krajcik, P.C. Blumenfeld, R.W. Marx, E. Soloway, A collaborative model for helping teachers learn project-based instruction. Elem. Sch. J. 94, 483-497 (1994)

G. Lacey, 3D printing brings designs to life. TechDirections 70(2), 17-19 (2010)

J. Lambert, Y. Gong, 21st century paradigms for pre-service teacher technology preparation. Comput. Sch. 27(1), 54-70 (2010)

R.C. Larson, M.E. Murray, Open educational resources for blended learning in high schools: Overcoming impediments in developing countries. J. Asynchronous Lear. Netw 12(1), 85-103 (2008)

Q. Li, Student and teacher views about technology: A tale of two cities? J. Res. Technol. Educ. 39(4), 377-397 (2007)

X. Li, J. Huan, in Proceedings of the 23rd ACM SIGKDD International Conference on Knowledge Discovery and Data Mining. Constructivism Learning: A Learning Paradigm for Transparent Predictive Analysis (Halifax, Canada, 2017)

H. Lipson, M. Kurman, Fabricated: The New World of 3D Printing (John Wiley \& Sons, Inc., Indianapolis, IN, 2013)

R. Lu, R.C. Overbaugh, School environment and technology implementation in K-12 classrooms. Comput. Sch. 26(2), 89-106 (2009) 
M.M. Maurer, G.S. Davidson, Leadership in Instructional Technology (Merrill, Columbus, OH, 1998)

H.M. Moorefield-Lang, Makers in the library: case studies of 3D printers and maker spaces in library settings. Library Hi Tech 32(4), 583-593 (2014)

S.V. Murphy, A. Atala, 3D bioprinting of tissues and organs. Nat. Biotechnol. 32, 773-785 (2014)

A. Nanjappa, M.M. Grant, Constructing on constructivism: The role of technology. Electron. J. Integr. Technol. Educ. 2(1), 38-56 (2003)

NGSS Lead States, Next Generation Science Standards: For States, by States (National Academies Press, Washington, DC, 2013)

J. Piaget, in Measurement and Piaget, ed. by D. R. Green, M. P. Ford, G. B. Flamer. The theory of stages in cognitive development (McGraw-Hill, New York, NY, 1971)

G.C. Rakes, V.S. Fields, K.E. Cox, The influence of teachers' technology use of instructional practices. J. Res. Technol. Educ. 38(4), 409-424 (2006)

J. Roland, (2015). Empowering teachers to implement technology-drive education. Accessed 28 June 2018, from https:// www.iste.org/explore/articleDetail?articleid $=569$

D. Russell, Y.K. Cho, E. Cylwik, Learning opportunities and career implications of experience with BIM/VDC. Pract. Period. Struct. Des. Constr. 19(1), 111-121 (2014)

C. Schelly, G. Anazalone, B. Wijnen, J.M. Pearce, Open-source 3-D printing technologies for education: Bringing additive manufacturing to the classroom. J. Vis. Lang. Comput. 28, 226-237 (2015)

D.H. Schunk, Coming to terms with motivation constructs. Contemp. Educ. Psychol. 25(1), 116-119 (2000)

S. Smith, Through the Teacher's eyes: Unpacking the TPACK of digital fabrication integration in middle school language arts. J. Res. Technol. Educ. 46(2), 207-227 (2013)

Solenoid. (n.d.). Retrieved July 05th, 2018, from http://www.yourdictionary.com/solenoid

H.A. Spires, J.K. Lee, K.A. Turner, J. Johnson, Having our say: Middle grade student perspectives on school, technologies, and academic engagement. J. Res. Technol. Educ. 40(4), 497-515 (2008)

N. Standish, FabNet invention kits: Outcomes and implementation (Unpublished Doctoral Dissertation) (University of Virginia, Charlottesville, VA, 2017)

N. Standish, R. Christensen, G. Knezek, W. Kjellstrom, E. Bredder, The effects of an engineering design module on student learning in a middle school science classroom. Int. J. Learn. Teach. Educ. Res. 15(6), 156-174 (2016)

A. R. Stansell, (2016). Transmedia STEM intervention book in middle school for educational change (Doctoral dissertation). Retrieved from UNT Theses and Dissertations. ark:/67531/metadc849609

T. Sundeen, D. Sundeen, Instructional technology for rural schools: Access and acquisition. Rural Special Education Quarterly 32(2), 8-14 (2013)

R.M. Tamim, R.M. Bernard, E. Borokhovski, P.C. Abrami, R.F. Schmid, What forty years of research says about the impact of technology on learning: A second-order meta-analysis and validation study. Rev. Educ. Res. 81(1), 4-28 (2011)

L. Thacker, (2017). The Internet crisis in rural America. Accessed 27 June 2018, from https://emergence. farmersbusinessnetwork.com/the-internet-crisis-in-rural-america

T. Tyler-Wood. Historical invention kits: A comparison of the achievement gains of high and low performing students in rural Texas, EduLearn 2018 Conference Proceedings, International Conference on Education and New Learning Technologies, Palma de Mallorca, Spain (2018)

E. Ültanir, (2012). An Epistemologic Glance at the Constructivist Approach: Constructivist Learning in Dewey, Piaget, and Montessori

L. Vygotsky, Interaction between Learning and Development. Mind and Society (Harvard University Press, Cambridge, MA, 1978)

Wheeler, T. (2014). Closing the digital divide in rural America. Accessed 28 June 2018, from https://www.fcc.gov/news-events/ blog/2014/11/20/closing-digital-divide-rural-america

C. Wood, Y. Kaszubowski, The career development needs of rural elementary students. Elem. Sch. J. 108(5), $431-444$ (2008)

R. Yager, The constructivist learning model. Sci. Teach. 58(6), 52 (1991)

G. Bull, J. Garofalo, M. Littman, R. Sherman, M. Hoffman, M. Grant, \& A. Grier, A. Make to learn: invention through emulation. Smart Learning Environments. 4(1), 8 (2017)

Federal Communications Commission. Broadband Progress Report. Accessed June 27, 2018, (2016), from https://www.fcc.gov/ reports-research/reports/broadband-progress-reports/2016-broadbandprogress-report

S. Ford, T. Minshall. Defining the Research Agenda for 3D Printing-Enabled Re-distributed Manufacturing. In: S. Umeda, M. Nakano, H. Mizuyama, H. Hibino, d. Kiritsis, G. von Cieminski (eds) Advances in Production Management Systems: Innovative Production Management Towards Sustainable Growth. APMS 2015. IFIP Advances in Information and Communication Technology, vol 460. Springer, Cham. (2015)

M. Wysession, D. Frank, S. Yancopoulos. Physical Science: Concepts in Action, Pearson Prentice Hall. (2011)

S.F. Loucks, B.W. Newlove \& G.E. Hall. Measuring Levels of Useof the Innovation: A manual for trainers, interviewers, and raters. Austin, TX: Research and Development Center for Teacher Education, the University of Texas, (1976).

R. Christensen. Effect of technology integration education on the attitudes of teachers and their students. Doctoral dissertation University of North Texas. [Online]. (1997), Available: http://courseweb.tac.unt.edu/rhondac. 